\title{
Surgical outcomes after endoscopic management of cholesterol granulomas of the petrous apex: a systematic review
}

\author{
Danielle F. Eytan, B.S., ${ }^{1}$ Varun R. Kshettry, M.D., ${ }^{2}$ Raj Sindwani, M.D., ${ }^{2-4}$ \\ Troy D. Woodard, M.D., ${ }^{2-4}$ and Pablo F. Recinos, M.D. ${ }^{2-4}$ \\ ${ }^{1}$ Cleveland Clinic Lerner College of Medicine; ${ }^{2}$ Rose Ella Burkhardt Brain Tumor and Neuro-Oncology \\ Center, Neurological Institute, Cleveland Clinic; ${ }^{3}$ Department of Otolaryngology, Head \& Neck Institute, \\ Cleveland Clinic; and ${ }^{4}$ Minimally Invasive Cranial Base \& Pituitary Surgery Program, Cleveland Clinic, \\ Cleveland, Ohio
}

\begin{abstract}
Object. Endoscopic endonasal treatment of petrous apex cholesterol granulomas allows for a natural drainage pathway into the nasopharynx. Because of the limited number of case series in the literature, there is limited evidence of recurrence rates and outcomes following endoscopic endonasal management. The purpose of this study was to determine the surgical outcomes of endoscopic endonasal approaches in the treatment of cholesterol granulomas of the petrous apex.

Methods. A systematic literature review was performed using PubMed for articles published from January 1980 to April 2014 to identify all studies reporting outcomes for endoscopic endonasal surgical management of cholesterol granulomas of the petrous apex. Operative approach, use of a stent, symptom outcome, restenosis, cyst recurrence, reoperation, and complications were extracted from included studies.

Results. A total of 53 patient cases were included from 22 relevant studies. The mean age was 41 years, and 26 patients $(49 \%)$ were female. Stents were used in $45.1 \%$ of cases. Symptom resolution or improvement was seen in $98.6 \%$ of cases at follow-up (mean follow-up 20 months). Complications were reported in $13.2 \%$ of cases, with the most common complication being epistaxis. Restenosis on follow-up office endoscopic examination occurred in 9 of 45 cases $(20.0 \%)$. Only 4 of these restenosis cases resulted in symptomatic cyst recurrence, resulting in an overall recurrence rate of $7.5 \%$. The mean time from surgery to cyst recurrence was 13.5 months. The rate of symptomatic cyst recurrence was $10.7 \%$ in cases without the use of a stent compared with $4.3 \%$ in cases with stent placement $(\mathrm{p}=0.6)$.

Conclusions. Based on current literature, endoscopic endonasal approaches result in a high rate of symptom improvement or resolution. Complication rates are lower than prior case series that have utilized open approaches. Asymptomatic restenosis can be managed conservatively, since it is associated with symptomatic cyst recurrence less than half of the time. This study revealed a nonsignificant trend toward a decrease in symptomatic cyst recurrence when a stent was used, but further work is needed to clarify its impact.

(http://thejns.org/doi/abs/10.3171/2014.7.FOCUS14344)
\end{abstract}

$\begin{array}{llclll}\text { KEY WORDS } & \text { cholesterol granuloma } & \text { c petrous apex } & \text { p petrous bone } \\ \text { endoscopic } & - & \text { endonasal }\end{array}$

$\mathrm{C}$ HOLESTEROL granulomas are uncommon cystic lesions that can present anywhere in the body, inology is unclear, they are thought to form when the air cells of the petrous apex are obstructed, thereby creating a vacuum into which blood is drawn and trapped. ${ }^{1,11,16,27}$ Another theory has more recently been proposed, which contends that exuberant pneumatization of the temporal bone leads to exposure of bone marrow-filled spaces in the petrous apex. ${ }^{20}$ This leads to a propensity for hemorrhage, and as hemorrhage and clotting occur, the petrous apex outflow tract is obstructed..$^{20}$ Regardless of the incit-

Abbreviations used in this paper: $\mathrm{ICA}=$ internal carotid artery; OCEBM = Oxford Centre for Evidence Based Medicine. ing event, the end result is the same; hemoglobin degradation products accumulate, cholesterol crystals form, and a granulomatous inflammatory reaction ensues. ${ }^{16,20}$

While cholesterol granulomas are benign lesions, their location in the petrous apex can produce local mass effect resulting in headaches, hearing loss, diplopia, and vertigo. A variety of treatment approaches have been described to decompress the mass effect caused by the lesion and establish a conduit for drainage of the air cells. Transcranial approaches include the middle cranial fossa, transcanal infracochlear, infralabyrinthine, transotic, and suboccipital approaches. ${ }^{3}$ More recently, endoscopic endonasal approaches have been used because the surgical approach itself reestablishes a natural drainage pathway into the nasopharynx with the potential benefits of faster 
recovery time and ease of office-based endoscopic follow-up. ${ }^{29}$

Because of the limited number of case series in the literature, there is limited evidence of recurrence rates following treatment. The purpose of this study was to systematically review the outcomes of endoscopic treatment of cholesterol granulomas of the petrous apex.

\section{Methods}

A PubMed search was performed using the term "cholesterol granuloma," which returned 722 results (Fig. 1-PRISMA flow diagram ${ }^{25}$ ). Resulting titles and abstracts were screened for relevant articles, resulting in 102 articles. Articles were included if they presented surgical outcomes related to endoscopic treatment of petrous apex cholesterol granulomas. Technical notes not presenting surgical outcome and radiographic studies were excluded. Cholesterol granulomas not primarily involving the petrous apex were excluded. Additional exclusion criteria included non-English-language articles; studies prior to 1980; and animal, cadaveric, and in vitro studies. There were no restrictions on publication status. Full text was assessed for eligibility criteria in the resulting 102 articles. For clinical studies using duplicate data, only the study with the most recent results were included. References of full-text articles were searched for any additional references not identified in the original search. The search period ended April 1, 2014.

Assessment of full-text articles resulted in 22 articles that met eligibility criteria and were included in the final systematic review. Data extraction from the 22 articles was independently conducted by 2 reviewers (D.F.E. and V.R.K.), and results were consistent. Strength of evidence of the included articles were assessed and assigned a score using the Oxford Centre for Evidence Based Medicine (OCEBM) Level of Evidence 2 classification system. ${ }^{18}$ Because none of the included studies were case-control or cohort studies, we could not apply the Newcastle-Ottawa Scale for nonrandomized studies. ${ }^{40}$

The association of use of a stent and recurrence of the cholesterol granuloma was evaluated using a 2-sided Fisher's exact test. A p value $<0.05$ was considered significant.

\section{Results}

The systematic review resulted in a total of 53 cases of endoscopic endonasal surgery for the treatment of petrous apex cholesterol granulomas (Table 1). There were 9 case series $8,10,13,17,19,29,31,33,38$ and 13 case reports., ${ }^{2,6,7}$, $12,21,23,24,28,30,32,34,36,39$ Since the first reported case in 1994, publications on the endoscopic endonasal approach to cholesterol granulomas of the petrous apex have in-

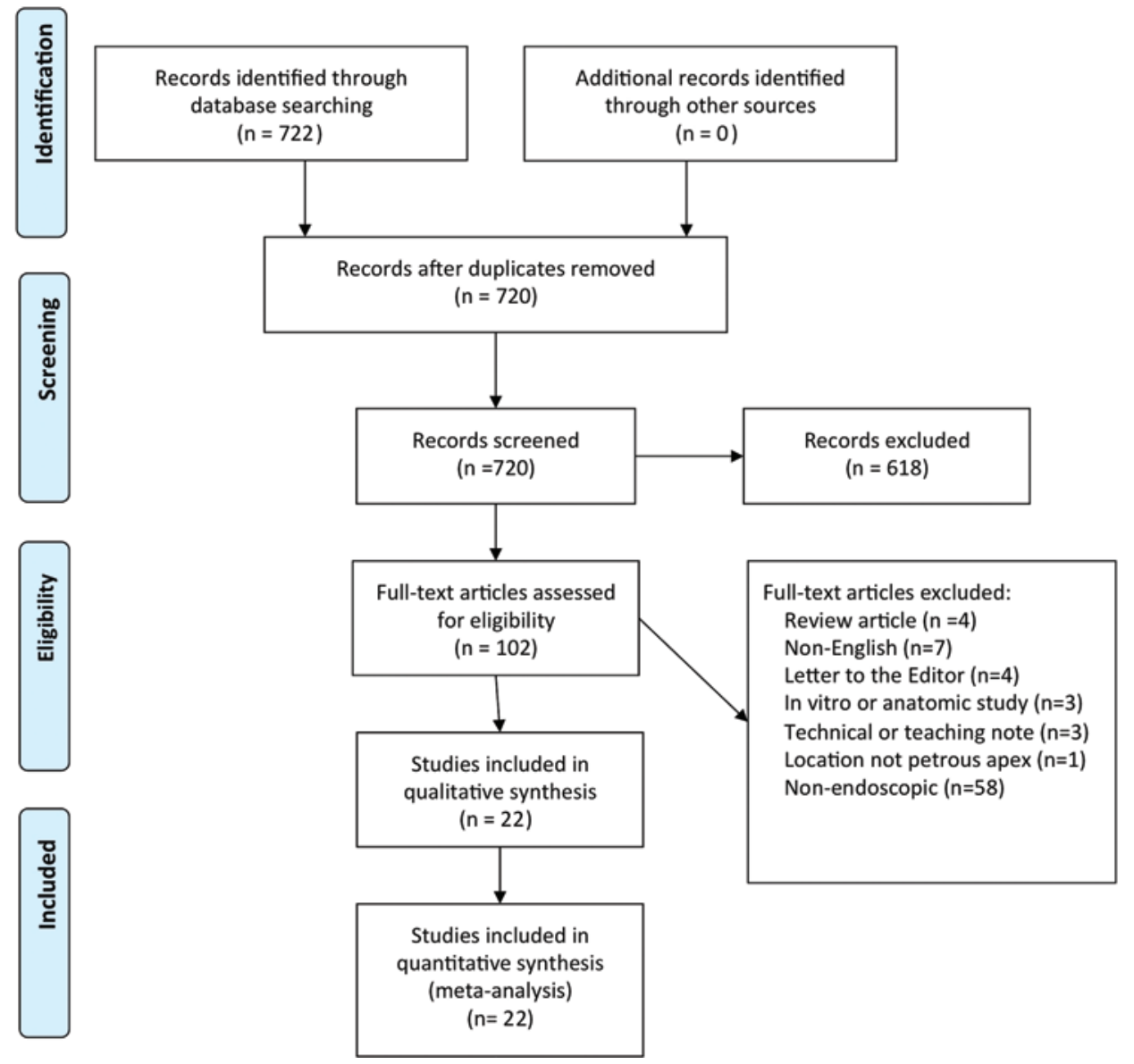

Fig. 1. Study selection process. 
Endoscopic treatment of petrous apex cholesterol granulomas

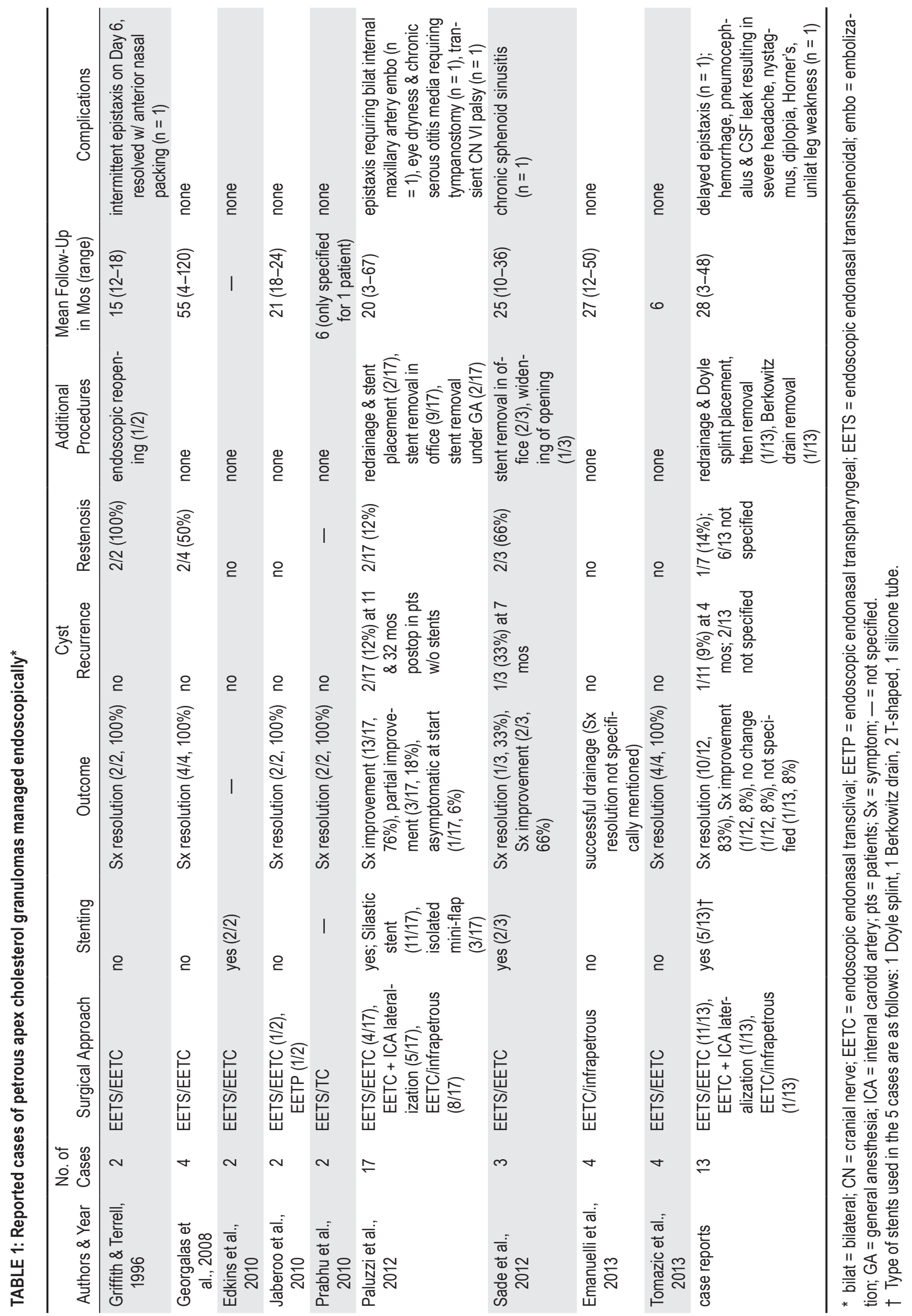


creased (Fig. 2). All included studies were case series or reports, and as such, all were Level 4 or 5 evidence based on the OCEBM classification system. Of the patients in these cases, 27 were male and 26 were female, with an age range of 13-78 years (mean 41 years, median 38 years). The follow-up duration ranged from 3 to 120 months (mean 20 months, median 11 months).

The petrous apex was most commonly approached via an endoscopic endonasal transsphenoidal transclival approach in $33(62.3 \%)$ of 53 cases, which includes cases in which the lesion eroded through the clivus into the sphenoid sinus. Endoscopic endonasal transclival with lateralization of the internal carotid artery (ICA) and a combined transclival/infrapetrous approach were used in $6(11.3 \%)$ and $13(24.5 \%)$ of the remaining cases, respectively, with the least common approach being the endoscopic endonasal transpharyngeal approach. Of the 51 cases in which it was stated that stenting was performed, stents were placed in $23(45.1 \%)$ and varied greatly across institutions and specific patient characteristics. Included in this group were 4 cases in which a vascularized nasoseptal mini-flap was used as a stent $(\mathrm{n}=3)$ or in addition to a stent $(\mathrm{n}=1)$ to prevent contraction of the fibrous cyst walls. ${ }^{29}$

Clinical outcome, with regard to symptomatology, was reported in 45 cases. The majority of patients postoperatively reported symptom resolution $(84.4 \%)$ or improvement (13.3\%). Of the 45 cases in which the degree of patency of the outflow track on follow-up endoscopic examination was noted, restenosis was observed in 9 cases $(20.0 \%)$. However, only 4 of these restenosis cases were associated with symptomatic cyst recurrence that required redrainage, resulting in an overall recurrence rate of $7.5 \%$. When stratifying by stent use, there was a $10.7 \%$ recurrence rate without the use of stents and $4.3 \%$ when they were used, which was not a statistically significant difference $(p=0.6)$.

There were 7 patients $(13.2 \%)$ with reported complications. These included epistaxis $(n=3)$, chronic otitis media requiring tympanostomy $(\mathrm{n}=1)$, chronic sphenoid sinusitis $(\mathrm{n}=1)$, and transient sixth nerve palsy $(\mathrm{n}=1)$. For 1 case serious complications were reported, with significant hemorrhage from the clival venous plexus requiring transfusion, a CSF leak, and tension pneumocephalus anterior to the frontal lobes, resulting in severe headache,

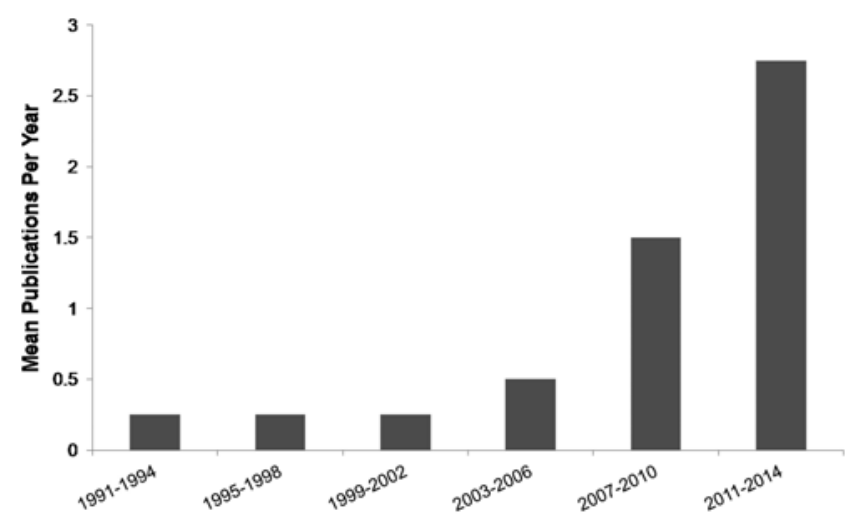

Fig. 2. Mean number of publications per year on the endoscopic endonasal management of petrous apex cholesterol granulomas. nystagmus, diplopia, and unilateral leg weakness. ${ }^{30}$ This patient was treated conservatively with $100 \%$ oxygen and bed rest in the supine position until the pneumocephalus and associated symptoms gradually resolved.

\section{Discussion}

Fucci et al. first reported the use of the endoscopic endonasal approach to treat a cholesterol granuloma of the petrous apex in $1994 . .^{12}$ Since then, endoscopic management has become increasingly used to treat these lesions. Because these lesions are relatively uncommon, evidence of outcomes after treatment with endoscopic approaches has been limited. The largest case series to date was of 17 patients reported by Paluzzi et al. ${ }^{29}$ In this study, we reviewed the collective evidence from 53 cases of endoscopic endonasal management of petrous apex cholesterol granulomas. The outcomes tallied from the 13 case reports were similar to those in the 9 case series identified; therefore, we included the case reports and felt they did not unfairly bias the results. Meaningful statistical evaluation for publication bias (e.g., funnel plot) was not feasible because of the limited number of series and small sample size per series. However, the possibility of publication bias, in regard to success rates and complications, remains a significant limitation of this study.

Irrespective of the approach used to drain the cholesterol granuloma, the commonly accepted definition of successful treatment is the absence of continuous growth in combination with an improvement in symptoms. In this study, we found that nearly all patients had at least some degree of symptom improvement and were thus successfully treated by an endoscopic approach. Reported success rates with open surgical approaches have been similar, with the largest published series reporting an $82 \%$ improvement of symptoms, ${ }^{3}$ but most smaller series reporting $90 \%-100 \%$ improvement. . $^{4,5,9,26}$

Because of the concern for recurrences, the use of stents has been proposed, although their true benefit has not been well established in the literature. Stenting remains at the discretion of the surgeon and can be based on multiple factors, including the size of the cyst opening, loss of mucosa, and proximity to the ICA ${ }^{33}$ In this study, we found that approximately $45 \%$ of patients had stents placed. Those patients largely did well, with only 1 (4.3\%) of 23 developing a symptomatic cyst recurrence, compared with $10.7 \%$ in the nonstented group. While this may reflect a trend toward superiority of stent use in preventing recurrence, this difference was not statistically significant. In addition, there is likely significant selection and institutional bias in determining which patients received stents. One might imagine that cysts that have a narrow corridor into the cyst might be more likely to have a stent placed, whereas cysts with significant extension into the sphenoid sinus may not require a stent after wide marsupialization of the cyst. However, one might expect the cholesterol granulomas with a narrow opening to have a higher recurrence rate regardless of stent placement, which would underestimate the true benefit of stenting. As additional cases of cholesterol granuloma of the petrous apex are performed endoscopically, the true 
Endoscopic treatment of petrous apex cholesterol granulomas

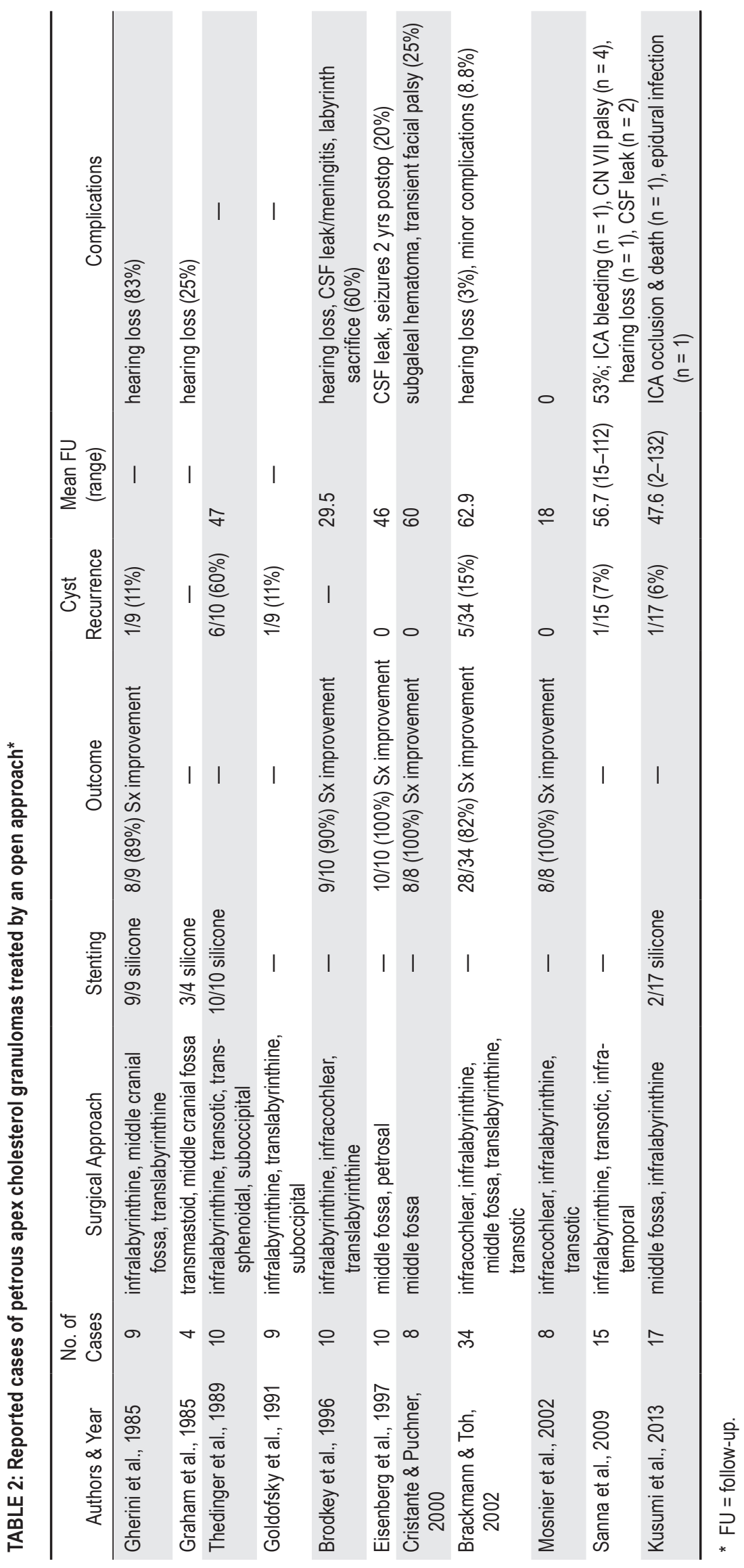


role of stenting will be more clearly determined. One interesting alternative to stenting is the use of a vascularized pedicle nasoseptal mucoperiostum "mini-flap," reported by Paluzzi et al. ${ }^{29}$ This not only serves the purpose of creating a mechanical barrier but may also promote the formation of mucosal lining along the cyst walls.

It is interesting to note the absence of a definitive association between restenosis of the drainage pathway and symptomatic cyst recurrence. While $20 \%$ of cases for which data were available noted restenosis on endoscopic follow-up examination, less than half of these were symptomatic cyst recurrences that required repeat operation. This suggests that a conservative approach is warranted when restenosis is observed on follow-up examination, with reoperation reserved only for cases in which significant symptoms recur.

When comparing overall recurrence rates and complications in the endoscopic cases to those found in previously published series of open approaches to cholesterol granulomas of the petrous apex (Table 2), this study confirms the safety and efficacy of endoscopic management. A literature review revealed 134 reported cases of petrous apex cholesterol granulomas treated by open approaches since $1980 .{ }^{3-5,9,14-16,22,26,35,37}$ Symptom improvement after open surgery appears to be similar to that obtained via endoscopic approaches. Six studies (79 patients) reported symptom outcome after open surgery for petrous apex cholesterol granulomas. . $^{3-5,9,14,26}$ Symptom improvement occurred in 71 patients $(90 \%)$. Nine studies (totaling 120 patients) reported the rate of cyst recurrence, which occurred in 15 patients (or $12.5 \%$ overall). The overall recurrence rate for endoscopic approaches found in this study was $7.5 \%$, which compares favorably with reported rates. Importantly, previous studies of open approaches report higher complication rates. Nine studies (115 patients) reported complication rates between $0 \%$ and $60 \%$, with a mean of $24.3 \% .^{3-5,9,14,16,22,26,35}$ In the present study, we found a lower rate of complications (13.2\%) with the endoscopic approaches. Additionally, the difference in the severity of reported complications is important to note. In open approaches, the reported complications have largely been hearing loss and CSF leak, whereas the most common complication in endoscopic cases was epistaxis, although 1 case did report CSF leak as well. While endoscopic endonasal approaches have demonstrated good safety and efficacy, not all petrous apex granulomas are surgically amenable to endonasal approaches. Preoperative imaging must be carefully studied to determine the approximate surgical corridor between the medial wall of the cyst and the lateral wall of the paraclival ICA. Lesions that are completely hidden behind the ICA may be more amenable to an open approach.

\section{Conclusions}

Based on current literature, endoscopic endonasal approaches provide a safe and effective approach to treatment of cholesterol granulomas of the petrous apex, with very high rates of symptom improvement or resolution. Complication rates are lower than those reported for prior case series utilizing open approaches. Restenosis on follow-up endoscopic examination occurs in about $20 \%$ of cases, but fewer than half of these cases are associated with symptomatic cyst recurrence. Therefore, asymptomatic stenosis of the drainage track can be managed conservatively. This study revealed a nonsignificant trend toward a decrease in symptomatic cyst recurrence when a stent was used, but further work is needed to clarify its impact.

\section{Disclosure}

The authors report no conflict of interest concerning the materials or methods used in this study or the findings specified in this paper.

Author contributions to the study and manuscript preparation include the following. Conception and design: Kshettry. Acquisition of data: Eytan, Kshettry. Analysis and interpretation of data: Eytan, Kshettry. Drafting the article: Eytan, Kshettry. Critically revising the article: all authors. Reviewed submitted version of manuscript: all authors. Approved the final version of the manuscript on behalf of all authors: Recinos. Statistical analysis: Eytan. Study supervision: Recinos.

\section{References}

1. Beaumont GD: The effects of exclusion of air from pneumatized bones. J Laryngol Otol 80:236-249, 1966

2. Bedrosian JC, Garcia-Navarro V, McCoul ED, Anand VK, Schwartz TH: Endoscopic balloon dilation as an adjunct to extended endoscopic approaches to the skull base. Case report. J Neurosurg 116:1215-1218, 2012

3. Brackmann DE, Toh EH: Surgical management of petrous apex cholesterol granulomas. Otol Neurotol 23:529-533, 2002

4. Brodkey JA, Robertson JH, Shea JJ III, Gardner G: Cholesterol granulomas of the petrous apex: combined neurosurgical and otological management. J Neurosurg 85:625-633, 1996

5. Cristante L, Puchner MA: A keyhole middle fossa approach to large cholesterol granulomas of the petrous apex. Surg Neurol 53:64-71, 2000

6. Dhanasekar G, Jones NS: Endoscopic trans-sphenoidal removal of cholesterol granuloma of the petrous apex: case report and literature review. J Laryngol Otol 125:169-172, 2011

7. DiNardo LJ, Pippin GW, Sismanis A: Image-guided endoscopic transsphenoidal drainage of select petrous apex cholesterol granulomas. Otol Neurotol 24:939-941, 2003

8. Edkins O, Lubbe D, Taylor A: Endoscopic trans-sphenoidal drainage of petrous apex cholesterol granulomas. S Afr J Surg 48:94-96, 2010

9. Eisenberg MB, Haddad G, Al-Mefty O: Petrous apex cholesterol granulomas: evolution and management. J Neurosurg 86:822-829, 1997

10. Emanuelli E, Ciorba A, Bianchini C, Bossolesi P, Stomeo F, Pelucchi S: Transnasal endoscopic management of petrous apex and clivus selected lesions. Eur Arch Otorhinolaryngol 270:1747-1750, 2013

11. Farrior B, Kampsen E, Farrior JB: The positive pressure of cholesterol granuloma idiopathic blue eardrum. Differential diagnosis. Laryngoscope 91:1286-1297, 1981

12. Fucci MJ, Alford EL, Lowry LD, Keane WM, Sataloff RT: Endoscopic management of a giant cholesterol cyst of the petrous apex. Skull Base Surg 4:52-58, 1994

13. Georgalas C, Kania R, Guichard JP, Sauvaget E, Tran Ba Huy P, Herman P: Endoscopic transsphenoidal surgery for cholesterol granulomas involving the petrous apex. Clin Otolaryngol 33:38-42, 2008

14. Gherini SG, Brackmann DE, Lo WW, Solti-Bohman LG: Cholesterol granuloma of the petrous apex. Laryngoscope 95: 659-664, 1985 


\section{Endoscopic treatment of petrous apex cholesterol granulomas}

15. Goldofsky E, Hoffman RA, Holliday RA, Cohen NL: Cholesterol cysts of the temporal bone: diagnosis and treatment. Ann Otol Rhinol Laryngol 100:181-187, 1991

16. Graham MD, Kemink JL, Latack JT, Kartush JM: The giant cholesterol cyst of the petrous apex: a distinct clinical entity. Laryngoscope 95:1401-1406, 1985

17. Griffith AJ, Terrell JE: Transsphenoid endoscopic management of petrous apex cholesterol granuloma. Otolaryngol Head Neck Surg 114:91-94, 1996

18. Howick J, Chalmers I, Glasziou P, Greenhalgh T, Heneghan C, Liberati A, et al: Oxford Centre for Evidence-Based Medicine 2011 Levels of Evidence. (http://www.cebm.net/wpcontent/uploads/2014/06/CEBM-Levels-of-Evidence-2.1.pdf) [Accessed August 19, 2014]

19. Jaberoo MC, Hassan A, Pulido MA, Saleh HA: Endoscopic endonasal approaches to management of cholesterol granuloma of the petrous apex. Skull Base 20:375-379, 2010

20. Jackler RK, Cho M: A new theory to explain the genesis of petrous apex cholesterol granuloma. Otol Neurotol 24:96-106, 2003

21. Korbmacher D, Lehmann M, Gehl HB, Ebmeyer J, Sudhoff $\mathrm{H}$ : Petrous apex cholesterol granuloma involving the sphenoid sinus. Ear Nose Throat J 90:E23-E25, 2011

22. Kusumi M, Fukushima T, Mehta AI, Cunningham CD III, Friedman AH, Fujii K: Middle fossa approach for total resection of petrous apex cholesterol granulomas: use of vascularized galeofascial flap preventing recurrence. Neurosurgery 72 (1 Suppl Operative): 77-86, 2013

23. McLaughlin N, Kelly DF, Prevedello DM, Shahlaie K, Carrau RL, Kassam AB: Endoscopic endonasal management of recurrent petrous apex cholesterol granuloma. Skull Base Rep 1:27-32, 2011

24. Michaelson PG, Cable BB, Mair EA: Image-guided transphenoidal drainage of a cholesterol granuloma of the petrous apex in a child. Int J Pediatr Otorhinolaryngol 57:165-169, 2001

25. Moher D, Liberati A, Tetzlaff J, Altman DG: Preferred reporting items for systematic reviews and meta-analyses: the PRISMA statement. PLoS Med 6:e1000097, 2009

26. Mosnier I, Cyna-Gorse F, Grayeli AB, Fraysse B, Martin C, Robier A, et al: Management of cholesterol granulomas of the petrous apex based on clinical and radiologic evaluation. Otol Neurotol 23:522-528, 2002

27. Ojala L: Pneumatization of the bone and environmental factors; experimental studies on chick humerus. Acta Otolaryngol Suppl 133:3-28, 1957

28. Oyama K, Ikezono T, Tahara S, Shindo S, Kitamura T, Teramoto A: Petrous apex cholesterol granuloma treated via the endoscopic transsphenoidal approach. Acta Neurochir (Wien) 149:299-302, 2007

29. Paluzzi A, Gardner P, Fernandez-Miranda JC, Pinheiro-Neto $\mathrm{CD}$, Scopel TF, Koutourousiou M, et al: Endoscopic endonasal approach to cholesterol granulomas of the petrous apex: a series of 17 patients. Clinical article. J Neurosurg 116:792798, 2012
30. Park KC, Wong G, Stephens JC, Saleh HA: Endoscopic transsphenoidal drainage of an aggressive petrous apex cholesterol granuloma: unusual complications and lessons learnt. J Laryngol Otol 127:1230-1234, 2013

31. Prabhu K, Kurien M, Chacko AG: Endoscopic transsphenoidal approach to petrous apex cholesterol granulomas. Br J Neurosurg 24:688-691, 2010

32. Presutti L, Villari D, Marchioni D: Petrous apex cholesterol granuloma: transsphenoid endoscopic approach. J Laryngol Otol 120:e20, 2006

33. Sade B, Batra PS, Scharpf J, Citardi MJ, Lee JH: Minimally invasive endoscopic endonasal management of skull base cholesterol granulomas. World Neurosurg 78:683-688, 2012

34. Samadian M, Vazirnezami M, Moqaddasi H, Rakhshan M, Khormaee F, Ashraf H: Endoscopic transrostral-transsphenoidal approach to petrous apex cholesterol granuloma: case report. Turk Neurosurg 19:106-111, 2009

35. Sanna M, Dispenza F, Mathur N, De Stefano A, De Donato G: Otoneurological management of petrous apex cholesterol granuloma. Am J Otolaryngol 30:407-414, 2009

36. Terranova P, Karligkiotis A, Gallo S, Meloni F, Bignami M, Castelnuovo P: A novel endoscopic technique for long-term patency of cholesterol granulomas of the petrous apex. Laryngoscope 123:2639-2642, 2013

37. Thedinger BA, Nadol JB Jr, Montgomery WW, Thedinger BS, Greenberg JJ: Radiographic diagnosis, surgical treatment, and long-term follow-up of cholesterol granulomas of the petrous apex. Laryngoscope 99:896-907, 1989

38. Tomazic PV, Nemetz U, Koele W, Walch C, Braun EM, Hammer GP, et al: Cholesterol granulomas of the petrous apex; endonasal endoscopic approach. B-ENT 9:263-267, 2013

39. Voormolen EH, Froelich S, Woerdeman PA, Berkelbach van der Sprenkel JW, Braunius WW, Regli L: Surgical instrument tracking optimizes trans-sphenoidal endoscopic treatment of petrous apex cholesterol granuloma. J Neurol Surg A Cent Eur Neurosurg 74:109-112, 2013

40. Wells GA, Shea B, O'Connell D, Peterson J, Welch V, Losos M, et al: The Newcastle-Ottawa Scale (NOS) for assessing the quality of nonrandomised studies in meta-analyses. Ottawa Hospital Research Institute. (http://www.ohri.ca/programs/ clinical_epidemiology/oxford.asp) [Accessed August 19, 2014]

Manuscript submitted June 15, 2014.

Accepted July 17, 2014.

Please include this information when citing this paper: DOI: 10.3171/2014.7.FOCUS14344.

Address correspondence to: Pablo F. Recinos, M.D., Section Head - Skull Base Surgery, Minimally Invasive Cranial Base and Pituitary Surgery Program, 9500 Euclid Ave., S-70, Cleveland, OH 44195. email: recinop@ccf.org. 